\title{
Sooting Tendencies of Unsaturated Esters in NONPREMIXED FLAMES
}

\author{
Dhrubajyoti D. Das ${ }^{\mathrm{a}, *}$, Charles S. McEnally ${ }^{\mathrm{a}}$, Lisa D. Pfefferle ${ }^{\mathrm{a}}$ \\ ${ }^{a}$ Yale University \\ Department of Chemical and Environmental Engineering, \\ 9 Hillhouse Ave, New Haven, CT 06511, USA
}

\begin{abstract}
Biodiesel fuels form an important constituent of the renewable energy resources landscape. These fuels are produced through transesterification of fatty acids with methanol or ethanol to yield long-chain methyl or ethyl esters of 16-18 carbon atoms, frequently with one or more $\mathrm{C}=\mathrm{C}$ double bonds. The $\mathrm{C}=\mathrm{C}$ double bonds are expected to play a major role in the combustion chemistry of these biodiesel fuels, especially in the area of soot emission. To better understand the effect of these double bonds on the sooting properties of esters, we have measured the sooting tendencies of twenty $\mathrm{C}_{4}$ to $\mathrm{C}_{7}$ unsaturated esters and report their Yield Sooting Indices (YSI). The $\mathrm{C}=\mathrm{C}$ double bond was found to have a significant effect on the sooting tendency. In most cases, the unsaturated ester was more sooting than its saturated counterpart, although the increase in sooting tendency was strongly influenced by other structural features of the compound. Esters with the $\mathrm{C}=\mathrm{C}$ double bond nearest the carbonyl group had lower increases in the sooting tendency from the parent saturated ester than compounds where the $\mathrm{C}=\mathrm{C}$ double bond was further along the carbon backbone. Unsaturated methyl esters had larger increases in YSI (compared to their parent saturated ester) than unsaturated ethyl or propyl esters. The strong dependence of the sooting tendencies of these esters on their chemical structure indicates the complexity of the chemical processes involved, and is an important area for further studies of these compounds.
\end{abstract}

Keywords: LII; biodiesel; soot; group additivity; YSI

\section{1. Introduction}

Exposure to airborne particulate matter has been known to adversely affect

human health. Many studies have reported an association between particulate

4 air pollution and mortality rates [1-4]. A recent systematic analysis of the

*Corresponding author
Email address: dhrubajyoti.das@yale.edu (Dhrubajyoti D. Das)

Preprint submitted to Combustion and Flame

November 11, 2014 
5 burden of disease and injury attributable to various risk factors concluded that 6 ambient particulate matter pollution and household air pollution from solid 7 fuels were two of the most important risk factors in reducing global human 8 life expectancy [4]. Soot forms an important portion of this particulate matter and has also been implicated as the second most important individual climate10 warming agent after carbon dioxide [5]. In this context, increasingly stringent soot emission regulations coupled with ever-increasing usage of hydrocarbon fuels for our various energy needs makes the study of soot in combustion particularly important.

Soot emission from combustion processes is strongly dependent on the structure of the fuel being burned [6-9]. A common way to quantify the differences in these emissions in a laboratory setting is through the use of sooting tendencies, measured for individual fuel or mixtures of fuels. For diffusion flames, sooting tendency has traditionally been characterized by a flame smoke height, and often converted into apparatus-independent measures such as threshold soot index (TSI) [10], or oxygen-extended sooting index (OESI) [11].

Our group has developed a new method of characterizing sooting tendency that does not involve the smoke height, but directly measures the maximum soot volume fraction $f_{\mathrm{v}, \max }$ in a flame [12-14]. In this method, a small amount of the test compound is added to a lightly sooting base flame, and the resulting increase in soot concentration is measured. The primary advantage of this method is that the amount of additive added to the base fuel - typically $1000 \mathrm{ppm}$ - is too small to affect soot concentrations through indirect mechanisms such as dilution of the base fuel or changes in the flame temperature; therefore the measured sooting tendencies depend strongly on the direct chemical effects of the test compound's structure. The experimentally measured $f_{\mathrm{v}, \max }$ are then converted into apparatus-independent Yield Sooting Indices (YSI) by the normalization equation:

$$
\mathrm{YSI}=A \times f_{\mathrm{v}, \max }+B
$$

where $A$ and $B$ are apparatus-specific parameters chosen such that the YSI of $n$-hexane $=0$, and the YSI of benzene $=100$.

Many recent studies in the literature have used YSI as a measure of the sooting tendencies of compounds relevant to combustion. We have measured the YSI of 62 volatile liquid aromatics [12], 72 non-volatile aromatics [13], 89 aliphatic hydrocarbons, and 186 oxygenated hydrocarbons [14]. Kashif et al. [15] have measured the YSI of several primary reference fuels and two-component blends of these fuels, as well as the effect of $\mathrm{CO}_{2}$ dilution of coflowing air on the YSI. Xuan and Blanquart [16] have numerically modeled the YSI of aromatic and non-aromatic species and achieved good agreement with the experimental values. Mensch et al. [17] have used the YSI of several hydrocarbons along with TSI measurements to compile a consistent set of sooting tendencies for a number of jet fuel surrogate compounds.

Biodiesel fuels are renewable alternatives to conventional diesel that have attracted significant research attention recently. Unlike petroleum-based diesel fuels, which contain hundreds or thousands of different chemical species including 
aromatic and aliphatic hydrocarbons, biodiesel fuels primarily contain esters $[18,19]$. These esters are generally produced through transesterification of fatty acids harvested from agricultural biomass [20]. Most biofuels derived from such sources contain both saturated and unsaturated esters, with the size and relative abundance of the individual esters dependent on the particular source of biomass. For example, unsaturated esters make up a large portion of the biodiesel from sources such as sunflower oil (88\%), soy (88\%), linseed oil (92\%), and rapeseed oil $(95 \%)$, but make up a smaller portion of the biodiesel from others like palm $(50 \%)$ and tallow (50\%) [19]. Figure 1 shows a small unsaturated ester, its corresponding saturated ester, and the alkene and alkane with the same number of carbon atoms.

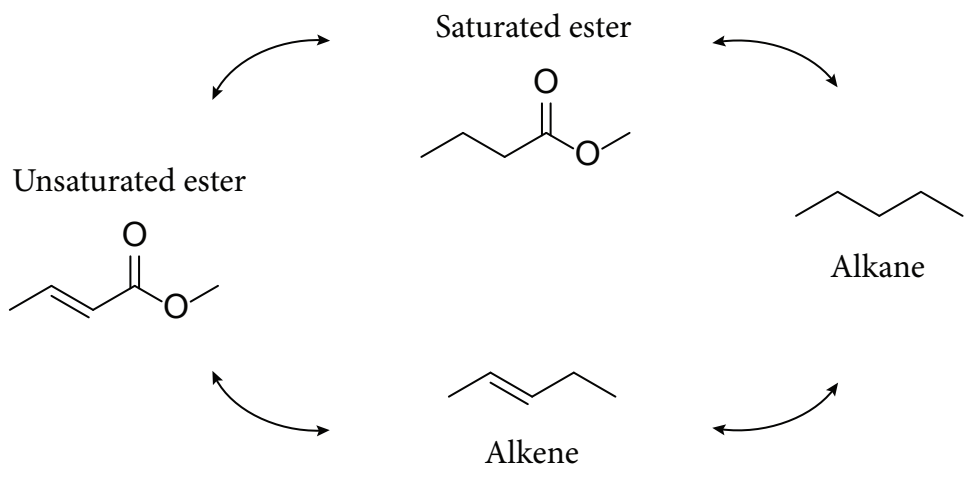

Figure 1: Chemical structure of a typical unsaturated ester (methyl 2-butenoate, or methyl crotonate) and its corresponding saturated ester (methyl butanoate), alkene (2-pentene), and alkane (pentane). The alkene and alkane can be thought of as deoxygenated versions of the unsaturated and saturated esters respectively.

The presence of oxygen atoms in these esters has important implications for their combustion chemistry. While several features of the combustion reactions for large esters are similar to those of large $n$-alkanes because of the common alkyl chains, many aspects of ester oxidation, such as the early formation of $\mathrm{CO}_{2}$ [18], cannot be produced by alkane reaction mechanisms. Saturated esters have also been shown to have lower sooting tendency than alkanes of the corresponding size and shape in laboratory flames $[11,14,21]$. Neat biodiesel fuel has also been noted to produce less soot than conventional diesel fuel under similar operating conditions in diesel engines [22]. The reduction in sooting tendency has been attributed to the higher oxygen content in the fuel [14, 19].

Unsaturation in biodiesel esters has potential implications for sooting behavior, since unsaturated bonds in hydrocarbons generally increase soot formation compared to saturated hydrocarbons [6-10, 14]. Various recent studies of esters in the literature have focused on the effect of the $\mathrm{C}=\mathrm{C}$ double bond on ester combustion. Sarathy et al. conducted oxidation experiments of two $\mathrm{C}_{4}$ (saturated and unsaturated) esters in jet stirred reactors and counterflow diffusion flames [23]; Gaïl et al. modeled the combustion products using a detailed chemical kinetic 
reaction mechanism [24]. They measured greater amounts of soot precursors such as $\mathrm{C}_{2} \mathrm{H}_{2}, 1-\mathrm{C}_{3} \mathrm{H}_{4}, 1-\mathrm{C}_{4} \mathrm{H}_{8}$, and $1,3-\mathrm{C}_{4} \mathrm{H}_{6}$ from the unsaturated ester. Yang et al. measured species concentrations of reaction intermediates in low-pressure premixed flames fueled with four saturated and unsaturated $\mathrm{C}_{4}[25]$, three saturated [26], and three unsaturated $\mathrm{C}_{5}$ [27] esters. They reported enhanced formation of oxygenated intermediates in the unsaturated ester flames. Zhang et al. [28] studied the oxidation of an unsaturated $\mathrm{C}_{6}$ ester at high pressures in a jet-stirred reactor, and compared the mole fractions of measured species to that of its saturated analog. They reported increased inhibition of low temperature oxidation, production of aldehydes like propanal at low temperatures, and more aldehydes and olefins at high temperatures in the case of unsaturated esters. In order to model the combustion of real biodiesels, kinetic mechanisms of larger unsaturated esters have also been developed [29-33]. Combustion mechanisms for smaller esters form an important foundation for all mechanisms developed for such larger esters [34].

Thus far, although the oxidation behavior of unsaturated esters has received some attention in the literature, their sooting behavior has not been addressed as extensively. Feng et al. [35] studied the sooting propensities of saturated and unsaturated esters in non-premixed counterflow flames. They measured soot volume fractions using laser extinction, and compared the experimental data against those obtained for flames fueled with $n$-alkanes of similar carbon numbers, and a surrogate diesel fuel. They studied 12 test compounds ranging from $\mathrm{C}_{4}$ to $\mathrm{C}_{12}$ including 3 unsaturated esters. Their results indicated that the presence of the methyl or ethyl ester functional group caused a significant decrease in the sooting tendency of the flame compared to an $n$-alkane with either the same or one or two less total carbon atoms. When comparing esters with the same carbon number, ethyl ester flames exhibited greater sooting propensity than methyl ester flames. When comparing saturated and unsaturated methyl esters with the same carbon number, the unsaturated ester had significantly higher sooting tendency. The exact position of the $\mathrm{C}=\mathrm{C}$ double bond in the ester, however, appeared to have only a slight, if any, impact on the sooting tendency. It should be noted that the compounds investigated in this study included only two unsaturated esters of the same size (and therefore different $\mathrm{C}=\mathrm{C}$ positions).

To better elucidate the effects of the $\mathrm{C}=\mathrm{C}$ double bond position as well as other structural features such as size and extent of branching on the sooting tendency of esters, a larger set of unsaturated esters with varied $\mathrm{C}=\mathrm{C}$ positions needed to be studied. In this paper, we report the YSI of 20 unsaturated esters (listed in Table 1). These test compounds were chosen to span a wide range of carbon numbers, location of $\mathrm{C}=\mathrm{C}$ double bonds, distribution of carbon atoms between the "ether" and "acid" side, and type of branching in the carbon backbone. We believe these are the most extensive sooting tendency measurements of unsaturated esters to be reported in the literature.

This paper is the fourth in a series of papers [12-14] that reports on the sooting tendency of hydrocarbons and oxygenated hydrocarbons. With the addition of sooting tendencies of unsaturated esters, our dataset includes YSI measurements of more than 400 alkanes, alkenes, alkynes, alcohols, aldehydes, 
ketones, carboxylic acids, ethers, esters, multi-oxygen compounds, volatile and non-volatile aromatics and cyclic compounds. To test whether the new results reported in this study are consistent with the previous experimental results, we have utilized a group additivity analysis based on the Benson method [36-38] to estimate the YSI of compounds in our dataset.

\section{Experimental methods}

The experimental setup used in this work is similar to that described earlier in [14]. Figure 2 shows a schematic of the experimental setup. Briefly, sooting tendencies of the unsaturated esters listed in Table 1 were determined by doping $1000 \mathrm{ppm}$ of each test compound into the fuel of a laboratory-scale burner and measuring the maximum mass concentration of soot in the resulting flames with laser-induced incandescence (LII) [12, 13]. These atmospheric-pressure coflow laminar nonpremixed flames were generated with a burner in which the fuel mixture $-55 \% \mathrm{CH}_{4}, 45 \% \mathrm{~N}_{2}$, and $1000 \mathrm{ppm}$ of the test compound - flows out of an $11 \mathrm{~mm}$ diameter tube and reacts with air that flows from the annular region between this tube and an outer chimney. The nominal reactant flow rates were $226 \mathrm{~cm}^{3} / \mathrm{min}$ of $\mathrm{N}_{2}, 274 \mathrm{~cm}^{3} / \mathrm{min}$ of $\mathrm{CH}_{4}, 0.5 \mathrm{~cm}^{3} / \mathrm{min}$ of test compound, and $50,000 \mathrm{~cm}^{3} / \mathrm{min}$ of air. The test compounds are all liquids at room temperature, and were injected into the gas-phase methane/nitrogen fuel mixture through a syringe pump. The syringe needle is introduced into the fuel line through a septum in a stainless steel tee. The fuel line and fuel tube are heated to $145{ }^{\circ} \mathrm{C}$ with temperature-controlled resistive tapes; all of the test compounds vaporized immediately upon injection and were swept to the flame as gases by the other fuel components. Each test compound was allowed to flow for at least 5 minutes before data acquisition began. Time-resolved soot measurements confirmed that all test compounds achieved adsorption/desorption equilibrium with the walls of the fuel line and fuel tube within this 5 minute interval. The liquid-phase flow rate through the syringe pump that corresponded to $1000 \mathrm{ppm}$ in the gas-phase for each test compound was calculated using the ideal gas law, the test-compound's molecular weight, and its liquid-phase mass density [39-41].

Soot volume fractions $\left(f_{\mathrm{v}}\right)$ were measured with LII. This technique of measuring soot has been used in our previous work [12-14], and elsewhere in the literature [42-46]. We generate the LII with the $1064 \mathrm{~nm}$ output of an Nd:YAG laser (Spectra-Physics DCR-3G). This excitation wavelength is attractive because it avoids any intereference from molecular fluorescence [47]. The beam is directed by a series of mirrors, focused with a lens of focal length $50 \mathrm{~cm}$, and passes through a $1 \mathrm{~mm} \varnothing$ ceramic aperture located $0.2 \mathrm{~m}$ in front of the burner before passing through the flame region and into a beam dump. The laser fluence is $0.8 \mathrm{~J} / \mathrm{cm}^{2}$, which is in the range where the LII signal is approximately independent of the fluence $[44,48]$. This independence of LII signal was confirmed by varying the laser fluence (with a half-wave plate and polarizing beam splitter, see Figure 2), and measuring the LII signal at different laser fluences. The LII is collected at right angles to the laser beam with a $f / 2$ silica lens and directed towards a photomultiplier tube (PMT; Hamamatsu R212). A cutoff 
filter (Coherent 35-3255) in front of the PMT limits the spectral range of the detected light to between 400 and $455 \mathrm{~nm}$. The PMT output is digitized at $500 \mathrm{Mhz}$ by an A/D converter (LeCroy LT342), averaged over 6000 shots of the $10 \mathrm{~Hz}$ laser, and integrated across a $20 \mathrm{~ns}$ window during the laser pulse ("signal") and another $20 \mathrm{~ns}$ window $150 \mathrm{~ns}$ before the pulse ("background"). The background is caused by offsets in the digitizer zero level and is subtracted from the signal to produce the final measurement of the soot volume fraction.

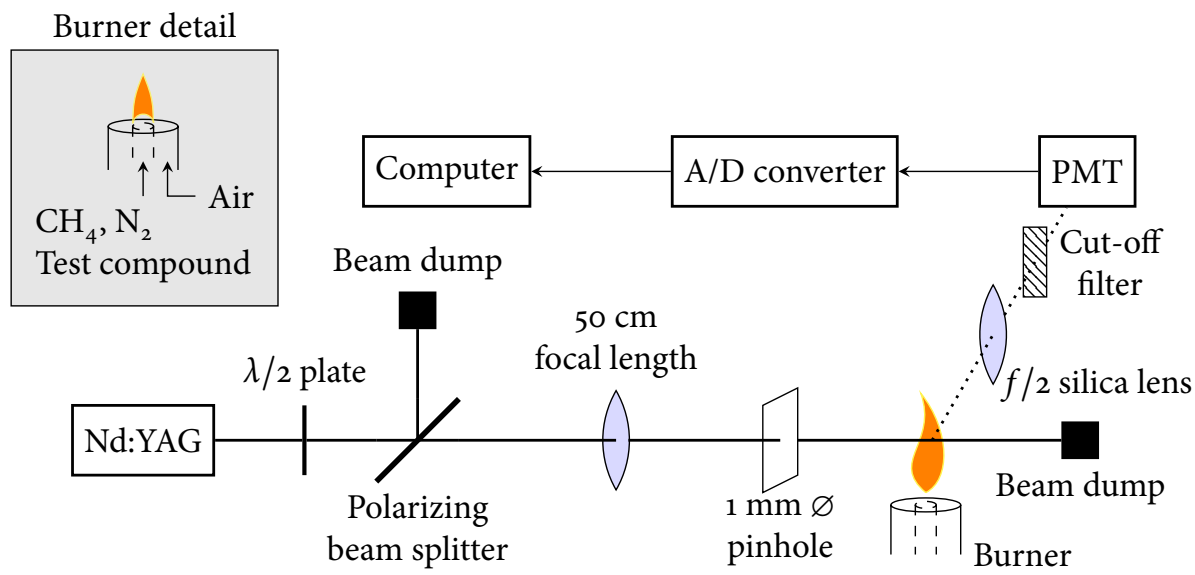

Figure 2: Experimental diagram. PMT: photomultiplier tube. The fuel and air coflow arrangment is shown in the burner detail inset. The burner is contained within a brass tube (not pictured) to isolate the flame from the lab environment.

We measured the LII signals of flames doped separately with benzene and $n$-hexane at dopant mole fractions in the fuel mixture ([dopant $]_{\text {fuel }}$ ) ranging from 400 to $1800 \mathrm{ppm}$. The data in Figure 3 show how the maximum centerline soot volume fraction $f_{\mathrm{v}, \max }$ (assumed to be proportional to the LII intensity) depends on [dopant $]_{\text {fuel }}$. The data closely fit the straight lines shown in the figure, indicating that the LII diagnostic depends linearly on soot volume fraction, with very high signal-to-noise ratio and low variance in sensitivity over the 5 hours required to measure both datasets. The choice of $1000 \mathrm{ppm}$ as [dopant] fuel in subsequent measurements is within this linear regime.

\section{Results and Discussion}

In this study we determined the sooting tendencies of 20 unsaturated esters by measuring their YSI. The full results are listed in Table 1 . These esters include linear and branched esters ranging from 4 to 7 carbon atoms, with methyl, ethyl, and propyl groups on the "ether" side of the ester. Isomers for esters in this range are numerous and span across a wide variety of chemical structures. The primary constraint on the compounds included in this study was the limited commerical availability of unsaturated esters with more than 8 carbon atoms. 


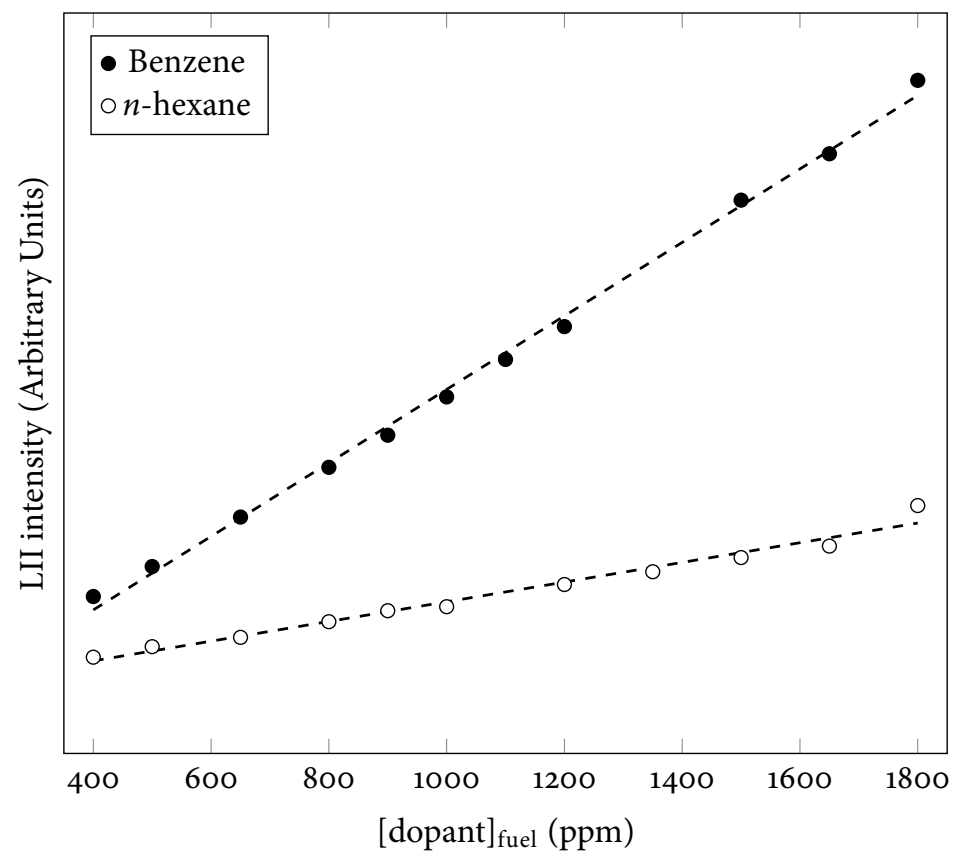

Figure 3: LII intensity plotted versus dopant concentration in the fuel. The LII signals were measured on the centerline at $30.4 \mathrm{~mm}$ above the burner in flames doped separately with benzene and $n$-hexane. The lines are least-squares fits to the data. A dopant concentration of $1000 \mathrm{ppm}$ was chosen for all subsequent experiments with other test compounds.

Table 1: List of unsaturated ester compounds and their Yield sooting indices (YSI) measured in this study

\begin{tabular}{|c|c|c|c|c|}
\hline Compound & Formula & CAS\# & YSI & Structure \\
\hline Methyl-2-propenoate (Methyl acrylate) & $\mathrm{C}_{4} \mathrm{H}_{6} \mathrm{O}_{2}$ & $96-33-3$ & -17.03 & \\
\hline Methyl-2-butenoate (Methyl crotonate) & $\mathrm{C}_{5} \mathrm{H}_{8} \mathrm{O}_{2}$ & $623-43-8$ & -4.71 & \\
\hline Methyl-2-methyl-2-propenoate (Methyl methacrylate) & $\mathrm{C}_{5} \mathrm{H}_{8} \mathrm{O}_{2}$ & $80-62-6$ & -2.16 & \\
\hline Methyl-2-pentenoate & $\mathrm{C}_{6} \mathrm{H}_{10} \mathrm{O}_{2}$ & $15790-88-2$ & 5.0 & \\
\hline Methyl-3-pentenoate & $\mathrm{C}_{6} \mathrm{H}_{10} \mathrm{O}_{2}$ & $818-58-6$ & 13.07 & \\
\hline Methyl-4-pentenoate & $\mathrm{C}_{6} \mathrm{H}_{10} \mathrm{O}_{2}$ & $818-57-5$ & 4.54 & \\
\hline Methyl-2-methyl-2-butenoate (Methyl tiglate) & $\mathrm{C}_{6} \mathrm{H}_{10} \mathrm{O}_{2}$ & $6622-76-0$ & 11.75 & \\
\hline
\end{tabular}

Continued on Next Page ... 


\begin{tabular}{|c|c|c|c|c|}
\hline Compound & Formula & $\mathrm{CAS} \#$ & YSI & Structure \\
\hline Methyl-3-methyl-2-butenoate & $\mathrm{C}_{6} \mathrm{H}_{10} \mathrm{O}_{2}$ & $924-50-5$ & 9.38 & \\
\hline Methyl-2-hexenoate & $\mathrm{C}_{7} \mathrm{H}_{12} \mathrm{O}_{2}$ & $13894-63-8$ & 8.58 & \\
\hline Methyl-3-hexenoate & $\mathrm{C}_{7} \mathrm{H}_{12} \mathrm{O}_{2}$ & 2396-78-3 & 23.10 & \\
\hline Methyl-5-hexenoate & $\mathrm{C}_{7} \mathrm{H}_{12} \mathrm{O}_{2}$ & $2396-80-7$ & 13.73 & \\
\hline Methyl-2-methyl-2-pentenoate & $\mathrm{C}_{7} \mathrm{H}_{12} \mathrm{O}_{2}$ & $1567-14-2$ & 18.05 & \\
\hline Ethyl-2-propenoate (Ethyl acrylate) & $\mathrm{C}_{5} \mathrm{H}_{8} \mathrm{O}_{2}$ & $140-88-5$ & -13.0 & \\
\hline Ethyl-2-butenoate (Ethyl crotonate) & $\mathrm{C}_{6} \mathrm{H}_{10} \mathrm{O}_{2}$ & $623-70-1$ & -0.10 & \\
\hline Ethyl-2-methyl-2-propenoate (Ethyl methacrylate) & $\mathrm{C}_{6} \mathrm{H}_{10} \mathrm{O}_{2}$ & $97-63-2$ & -7.67 & \\
\hline Ethyl-4-pentenoate & $\mathrm{C}_{7} \mathrm{H}_{12} \mathrm{O}_{2}$ & $1968-40-7$ & 16.78 & \\
\hline Ethyl-2-methyl-2-butenoate (Ethyl tiglate) & $\mathrm{C}_{7} \mathrm{H}_{12} \mathrm{O}_{2}$ & $5837-78-5$ & 5.62 & \\
\hline Ethyl-3-methyl-2-butenoate (Ethyl-3,3-dimethylacrylate) & $\mathrm{C}_{7} \mathrm{H}_{12} \mathrm{O}_{2}$ & $638-10-8$ & 14.24 & \\
\hline Propyl-2-propenoate (Propyl acrylate) & $\mathrm{C}_{6} \mathrm{H}_{10} \mathrm{O}_{2}$ & $925-60-0$ & -0.56 & \\
\hline Propyl-2-methyl-2-propenoate (Propyl methacrylate) & $\mathrm{C}_{7} \mathrm{H}_{12} \mathrm{O}_{2}$ & $2210-28-8$ & 10.53 & \\
\hline
\end{tabular}

\subsection{Uncertainties}

There were two main sources of uncertainty in the measured YSI. The first is stochastic variations due to finite precision of the LII diagnostic. The experimental procedure for each compound involved measuring the LII signal of a benzene or $n$-hexane doped flame between every test compound in the following order:

benzene $\rightarrow$ test compound $\# 1 \rightarrow n$-hexane $\rightarrow$ test compound $\# 2 \rightarrow$ benzene $\rightarrow$ test compound $\# 3 \rightarrow n$-hexane $\rightarrow \ldots$

Thus every test compound measurement was buttressed by a benzene $/ n$-hexane measurement performed immediately before and after the test compound. This set of benzene/ $n$-hexane/test compound measurements for each compound was used to calculate its YSI as per Eq 1, minimizing any errors due to a systematic drift in the LII diagnostic signal over the course of the experiment. Finally, this procedure was repeated until there were at least three sets of YSI values for each test compound; the values listed in Table 1 are the average of the three readings. The second source of uncertainity is from variations in the literature value of liquid-phase densities of the test compounds. The densities were essential in 
calculating the liquid flow rate of the test compounds corresponding to 1000 ppm in the gas phase. Overall, we estimate an uncertainty of \pm 2 YSI for the quoted YSI values of each compound in Table 1.

\subsection{Effect of $C=C$ double bond}

In our previous work on the sooting tendency of oxygenated hydrocarbons [14], we measured the YSI of 44 saturated esters and carboxylic acids. Most of the test compounds in this study are unsaturated analogs of those saturated esters, and therefore comparing the YSI of these two types of compounds provides a quantitative picture of the effect of the $\mathrm{C}=\mathrm{C}$ double bond on sooting tendency. The slopegraph in Figure 4 compares the YSI of the unsaturated esters measured in this study with the YSI of their saturated analogs (as well as alkanes, which are discussed in Section 3.3) reported in [14]. The red circles on the left side of the graph indicate different unsaturated esters; each unsaturated ester is connected to its analogous saturated ester, indicated by blue circles, in the middle of the graph. The data points are arranged according to their YSI. Since one saturated ester can have a $\mathrm{C}=\mathrm{C}$ double bond in many different locations, some of the lines originating from the left side of the graph terminate at the same point in the middle.

In most cases, we see that the unsaturated esters have a larger YSI, and therefore a greater propensity to form soot than the corresponding saturated ester. In other words, addition of a $\mathrm{C}=\mathrm{C}$ double bond increases the amount of soot produced during combustion, which is consistent with previous findings on the effects of molecular structure on soot formation [6, 14]. The increase in sooting tendency is not uniform across different compounds (the lines are not parallel to each other). Since all of the tested compounds were monounsaturated, this indicates that besides the degree of unsaturation, the structure of the parent molecule is also important in determining the rise in soot production among different compounds. The location of the $\mathrm{C}=\mathrm{C}$ double bond also clearly plays a major role in the amount of soot produced. In most cases where one saturated ester leads to multiple unsaturated esters, these unsaturated esters have significantly different YSI values from one another, indicating that from the perspective of sooting tendencies, where the $\mathrm{C}=\mathrm{C}$ double bond is introduced into the carbon backbone of the compound is important.

\subsection{Effect of $O$ atoms}

Alkanes are the main components of all petroleum-derived fuels; thus they establish the baseline for evaluating the effects of oxygenates on soot formation. Since biodiesel is composed of saturated and unsaturated esters, comparing the YSI of these compounds with their structurally analogous alkanes provides insight into the effect of addition of both oxygen and $\mathrm{C}=\mathrm{C}$ double bond to the base compound. Figure 4 shows a slopegraph indicating the YSI of alkanes relative to the YSI of unsaturated and saturated esters. The two saturated esters in Figure 4 without analogous alkanes in our dataset are methyl propionate and methyl isobutyrate. 
It is seen from Figure 4 that, to within experimental uncertainty ( \pm 2 YSI units), all saturated esters have a lower YSI than their corresponding alkane. This is consistent with the expected soot reduction behavior when an oxygen atom is added to a hydrocarbon. However, in many cases, the subsequent addition of the $\mathrm{C}=\mathrm{C}$ double bond causes such a large increase in the YSI (when comparing the YSI of the unsaturated ester with its parent alkane), that it completely counteracts the beneficial soot reduction properties of the added $\mathrm{O}$ atoms. The changes in the YSI are not uniform and depend on specific structural details which are discussed in the next section.

\subsection{Structure specific effects on YSI}

The location of the $\mathrm{C}=\mathrm{C}$ double bond relative to the carbonyl group in the unsaturated ester is important in determining the compound's sooting tendency. Compounds where the carbon atom right next to the carbonyl group is connected to a neighboring carbon atom with a double bond (such as methyl 2-pentenoate) have lower increases in YSI (compared to their parent ester) than compounds where the $\mathrm{C}=\mathrm{C}$ double bond is further away from the carbonyl group (methyl 3 -pentenoate). This can be seen in Figure 5, where unsaturated esters with $\mathrm{C}=\mathrm{C}$ further away from the carbonyl group (such as methyl 3-pentenoate or ethyl 4-pentenoate) are highlighted in red. Going from the parent alkane to the saturated ester to the unsaturated ester, these compounds have a greater increase in YSI than other compounds (gray colored lines).

The "ether" moeity of the ester is also important in determining the compound's sooting tendency. Generally, unsaturated methyl esters had larger increases in the YSI from their saturated counterparts compared to ethyl and propyl esters. This can be seen in the slopegraph in Figure 6, where methyl ester families have been highlighted. For unsaturated esters with the same structure and carbon number but different "ether" moeities, (for example, methyl crotonate and ethyl acrylate, which are both $\mathrm{C}_{5} \mathrm{H}_{8} \mathrm{O}_{2}$ ) the methyl ester had a greater sooting tendency than the ethyl or propyl ester. From Table 1, we see this to be true for methyl crotonate $(\mathrm{YSI}=-4.71)$ vs ethyl acrylate $(\mathrm{YSI}=$ -13.0 ), methyl 2-pentenoate (5.0) vs ethyl crotonate $(-0.1)$ or propyl acrylate $(-0.56)$, and methyl tiglate $(11.75)$ vs ethyl methacrylate $(-7.67)$. This trend is consistent with smoke point measurements of methyl crotonate and ethyl acrylate by Barrientos et al. [11].

\subsection{Group additivity analysis}

Group contribution methods consist of subdividing a chemical compound into a set of simple structural elements in such a way that the property of interest of the original compound can be calculated from constants associated with the individual structural elements. Each structural element has a specific numerical contribution to the overall property, and these contributions are additive. Group contribution methods to estimate various physical and chemical properties of compounds have been used extensively in the literature [49, 50]. In particular, they have been used to estimate the sooting tendency of hydrocarbons. 
Pepiot-Desjardins et al. [21] used the Benson group contribution method to interpret experimental observations on the effect of oxygenated additives of hydrocarbon fuels. Their analysis was carried out on several experimental databases encompassing both premixed and nonpremixed configurations and utilized smoke points, soot volume fraction measurements in flames and simuations of rich premixed homogenous reactors. Barrientos et al. [11] used the structural group additivity method to interpret experimental observations on the effect of oxygen functional groups on the sooting tendency of oxygenated fuels. They also utilized the smoke point, expressed in terms of the Oxygen Extended Sooting Index (OESI), to study an expanded set of $\mathrm{C}_{5}$ oxygenated hydrocarbons. Both studies confirmed that oxygen content as well as molecular structure and imbedded functional groups influence the sooting tendency of a compound.

The Benson group additivity theory used here [36-38] was initially developed to estimate thermodynamic properties of molecules for which no experimental data were available. This method accounts for nearest-neighbor interactions in the structural sub-units of a compound. Every polyvalent atom in the molecule together with all of its ligands are considered a group. This method has typically had difficulty evaluating cyclic molecules without introducing ad hoc correction factors [38]. We have therefore excluded aromatic and cyclic aliphatic compounds from the present analysis.

A total of 265 compounds (including the 20 reported in this study) were considered; these included alkanes, alkenes, alcohols, aldehydes, ketones, carboxylic acids, ethers, esters, and multi-oxygen compounds. Their sizes ranged from compounds $\mathrm{C}_{1}$ (methanol) to $\mathrm{C}_{12}$ ( $n$-dodecane) hydrocarbons. These compounds were decomposed into 35 different groups (Table 2). We have represented the groups following Benson's notation. The polyvalent atom is written in bold face, and its ligands are specified inside parentheses. Some linearly interdependent groups, such as $\mathbf{C}-(\mathrm{O})(\mathrm{H})_{3}, \mathbf{C}-(\mathrm{C})(\mathrm{H})_{3}$, and $\mathbf{C}-(\mathrm{CO})(\mathrm{H})_{3}$, are not distinguished as per Benson's recommendation [21, 38].

The YSI of a compound could be expressed as a linear combination of the contributions of each of these groups weighted by the number of occurences of each group in a compound.

$$
\text { YSI }(\text { predicted })=\sum_{j} N_{i j} C_{j}
$$

where $N_{i j}$ is the number of groups of type $j$ in compound $i$, and $C_{j}$ is the specific contribution of group $j$. The various coefficients $C_{j}$ for each group were computed through least-squares fitting of Eq 2 to the experimental YSI; this can be cast as an optimization problem.

$$
\left.\min \chi^{2}=\sum_{k=1}^{n}[\text { YSI (experimental) }- \text { YSI (predicted })\right]^{2}
$$

Table 2 lists the 35 different groups and their optimized sooting contributions $C_{j}$. Figure 7 shows the correlation between YSI (predicted) and YSI (experimental) 
332

Table 2: Group additivity contributions of 35 different groups to the YSI, based on experimentally determined YSI of 265 compounds.

\begin{tabular}{|c|c|c|c|}
\hline ID & End Group & Occurences & Contribution \\
\hline 1 & $\mathrm{O}-(\mathrm{C})(\mathrm{H})$ & 62 & -28.7 \\
\hline 2 & $\mathrm{O}-(\mathrm{CO})(\mathrm{H})$ & 5 & -22.4 \\
\hline 3 & $\begin{array}{l}\mathbf{C O}-(\mathrm{O})(\mathrm{H}) \\
\mathbf{C O}-(\mathrm{C})(\mathrm{H})\end{array}$ & 26 & -22.0 \\
\hline 4 & $\begin{array}{l}\mathbf{C}-(\mathrm{O})(\mathrm{H})_{3} \\
\mathbf{C}-(\mathrm{C})(\mathrm{H})_{3} \\
\mathbf{C}-(\mathrm{CO})(\mathrm{H})_{3}\end{array}$ & 602 & -14.5 \\
\hline 5 & $\mathbf{C}-\left(\mathrm{C}_{\mathrm{d}}\right)(\mathrm{H})_{3}$ & 43 & -10.8 \\
\hline 6 & $\mathbf{C}_{\mathbf{d}}-(\mathrm{H})_{2}$ & 27 & -9.2 \\
\hline ID & Mid Group & Occurences & Contribution \\
\hline 7 & $\mathbf{C O}-(\mathrm{O})_{2}$ & 3 & -10.1 \\
\hline 8 & $\mathrm{O}-(\mathrm{C})_{2}$ & 57 & -9.4 \\
\hline 9 & $\mathbf{C}_{\mathbf{d}}-(\mathrm{CO})(\mathrm{H})$ & 10 & -5.6 \\
\hline 10 & $\mathbf{C O}-(\mathrm{O})(\mathrm{C})$ & 42 & -3.7 \\
\hline 11 & $\mathrm{O}-(\mathrm{C})(\mathrm{CO})$ & 67 & 2.3 \\
\hline 12 & $\mathrm{CO}-(\mathrm{C})_{2}$ & 28 & 2.8 \\
\hline 13 & $\mathbf{C}-(\mathrm{CO})(\mathrm{C})(\mathrm{H})_{2}$ & 63 & 5.5 \\
\hline 14 & $\mathbf{C O}-(\mathrm{O})\left(\mathrm{C}_{\mathrm{d}}\right)$ & 16 & 5.6 \\
\hline 15 & $\mathbf{C}-(\mathrm{CO})\left(\mathrm{C}_{\mathrm{d}}\right)(\mathrm{H})_{2}$ & 2 & 7.0 \\
\hline 16 & $\mathbf{C}-(\mathrm{C})\left(\mathrm{C}_{\mathrm{d}}\right)(\mathrm{H})_{2}$ & 43 & 8.7 \\
\hline 17 & $\mathbf{C}-(\mathrm{C})_{2}(\mathrm{H})_{2}$ & 404 & 8.8 \\
\hline 18 & $\mathbf{C}-(\mathrm{C})(\mathrm{O})(\mathrm{H})_{2}$ & 107 & 9.5 \\
\hline 19 & $\mathbf{C}-(\mathrm{O})_{2}(\mathrm{H})_{2}$ & 2 & 13.8 \\
\hline 20 & $\begin{array}{l}\mathbf{C}_{\mathbf{d}}-(\mathrm{C})(\mathrm{H}) \\
\mathbf{C}_{\mathbf{d}}-(\mathrm{CO})(\mathrm{C})\end{array}$ & 58 & 17.6 \\
\hline 21 & $\mathbf{C}-(\mathrm{C})(\mathrm{O})_{2}(\mathrm{H})$ & 3 & 29.2 \\
\hline 22 & $\mathbf{C}-(\mathrm{CO})(\mathrm{C})_{2}(\mathrm{H})$ & 19 & 31.8 \\
\hline 23 & $\mathbf{C}-(\mathrm{CO})(\mathrm{O})_{2}(\mathrm{H})$ & 1 & 35.1 \\
\hline
\end{tabular}

Continued on Next Page ... 


\begin{tabular}{llrc}
\hline ID & Mid Group & Occurences & Contribution \\
\hline 24 & $\mathbf{C}-(\mathrm{O})(\mathrm{C})_{2}(\mathrm{H})$ & 38 & 37.1 \\
25 & $\mathbf{C}-(\mathrm{C})_{3}(\mathrm{H})$ & 61 & 40.0 \\
26 & $\mathbf{C}_{\mathbf{d}}-(\mathrm{C})_{2}$ & 19 & 43.7 \\
27 & $\mathbf{C}-(\mathrm{O})_{3}(\mathrm{H})$ & 1 & 44.3 \\
28 & $\mathbf{C}-(\mathrm{C})_{2}\left(\mathrm{C}_{\mathrm{d}}\right)(\mathrm{H})$ & 4 & 44.7 \\
29 & $\mathbf{C}-(\mathrm{O})_{2}(\mathrm{C})_{2}$ & 1 & 54.9 \\
30 & $\mathbf{C}-(\mathrm{O})_{3}(\mathrm{C})$ & 1 & 58.5 \\
31 & $\mathbf{C}-(\mathrm{O})(\mathrm{C})_{3}$ & 14 & 66.2 \\
32 & $\mathbf{C}-(\mathrm{CO})(\mathrm{C})_{3}$ & 6 & 66.8 \\
33 & $\mathbf{C}-(\mathrm{C})_{4}$ & 17 & 70.9 \\
34 & $\mathbf{C}-(\mathrm{O})_{4}$ & 1 & 71.2 \\
35 & $\mathbf{C}-(\mathrm{C})_{3}\left(\mathrm{C}_{\mathrm{d}}\right)$ & 3 & 83.7 \\
\hline
\end{tabular}

\subsection{YSI and heating value}

Oxygenated compounds generally have a lower sooting tendency than alkanes or alkenes of similar size, which could result in lower soot emissions when such compounds are used as fuels. However, oxygenated compounds also have lower heats of combustion than hydrocarbons with the same carbon number. This could lead to a situation where reductions in soot emissions achieved by use of an inherently less sooty fuel might be negated by the necessity of using greater quantities of the less sooty fuel due to its lower caloric value. Figure 8 shows the relationship between the molar higher heating value and YSI for different compounds reported in this study and in the literature [14]. The heating value of these compounds was calculated using their gas phase enthalpy of formation from [51]. These enthalpies of formation were either determined experimentally or estimated using group contribution methods. The compounds include alkanes and alkenes in the $\mathrm{C}_{5}$ to $\mathrm{C}_{7}$ range, and saturated and unsaturated esters in the $\mathrm{C}_{4}$ to $\mathrm{C}_{7}$ range. It can be seen that the heating value correlates well with the number of carbon atoms in the compound; both unsaturated and saturated esters have similar heating values compared to alkanes and alkenes with one less carbon atom. In other words, the expected increase in the heating value of the esters due to the presence of the carboxylic carbon atom is approximately compensated with a reduction in heating value due to the oxidation state of the carboxylic carbon atom. Comparing $\mathrm{C}_{6}$ alkanes and alkenes to $\mathrm{C}_{7}$ esters (in the $4000-4500 \mathrm{~kJ} / \mathrm{mol}$ range) shows that within a comparable range of heating values, the sooting tendency of the compounds extends over a wide range. This indicates that for esters and aliphatic hydrocarbons in the $\mathrm{C}_{4}$ to $\mathrm{C}_{7}$ size range, other things being equal, it is possible to reduce soot emissions in flames and practical combustion devices through the use of oxygenated hydrocarbons without significant losses in fuel caloric value. 


\section{Conclusions}

We have measured the sooting tendencies of 20 unsaturated esters in the $\mathrm{C}_{4}$ to $\mathrm{C}_{7}$ range. These esters were selected to span a wide range of chemical structures and location of $\mathrm{C}=\mathrm{C}$ double bonds in the carbon backbone. Generally, introduction of the $\mathrm{C}=\mathrm{C}$ double bond into the ester increased its sooting tendency considerably compared to its saturated ester counterpart. In some cases this increase in sooting tendency was large enough to completely counteract any beneficial soot reduction due to presence of the oxygen atoms in the parent alkane. The increase in sooting tendency was not uniform for all tested compounds, and was strongly dependent on various structural features. One such structural feature was the location of the $\mathrm{C}=\mathrm{C}$ double bond relative to the carbonyl group of the ester. Compounds where the $\mathrm{C}=\mathrm{C}$ double bond was nearest to the carbonyl group had relatively smaller increases in sooting tendency (compared to the saturated ester) compared with compounds where the double bond was further down the backbone. Unsaturated methyl esters were found to have greater YSI and larger increases in sooting tendency (from the parent saturated ester) than unsaturated ethyl or propyl esters. Group additivity analysis using the Benson method was performed on the YSI of a large dataset of hydrocarbons and oxygenated hydrocarbons including unsaturated esters reported in this study and other compounds reported in previous studies. The predicted YSI using 35 groups correlated well with the experimental YSI of 265 compounds.

Given the increase in sooting tendency of unsaturated esters compared to saturated esters, from a soot emission perspective, other things being equal, it is beneficial to use saturated oils as fuels in biodiesel. However, the strong dependence of the sooting tendency on the structure of the esters is an indicator of the rich complexity of chemical processes involved, and is an area for further kinetic studies of these compounds.

\section{Acknowledgments}

We thank the National Science Foundation (CTS-1122311) and NSF/US Department of Energy Partnership on Advanced Combustion Engines (1258654) for financial support. 


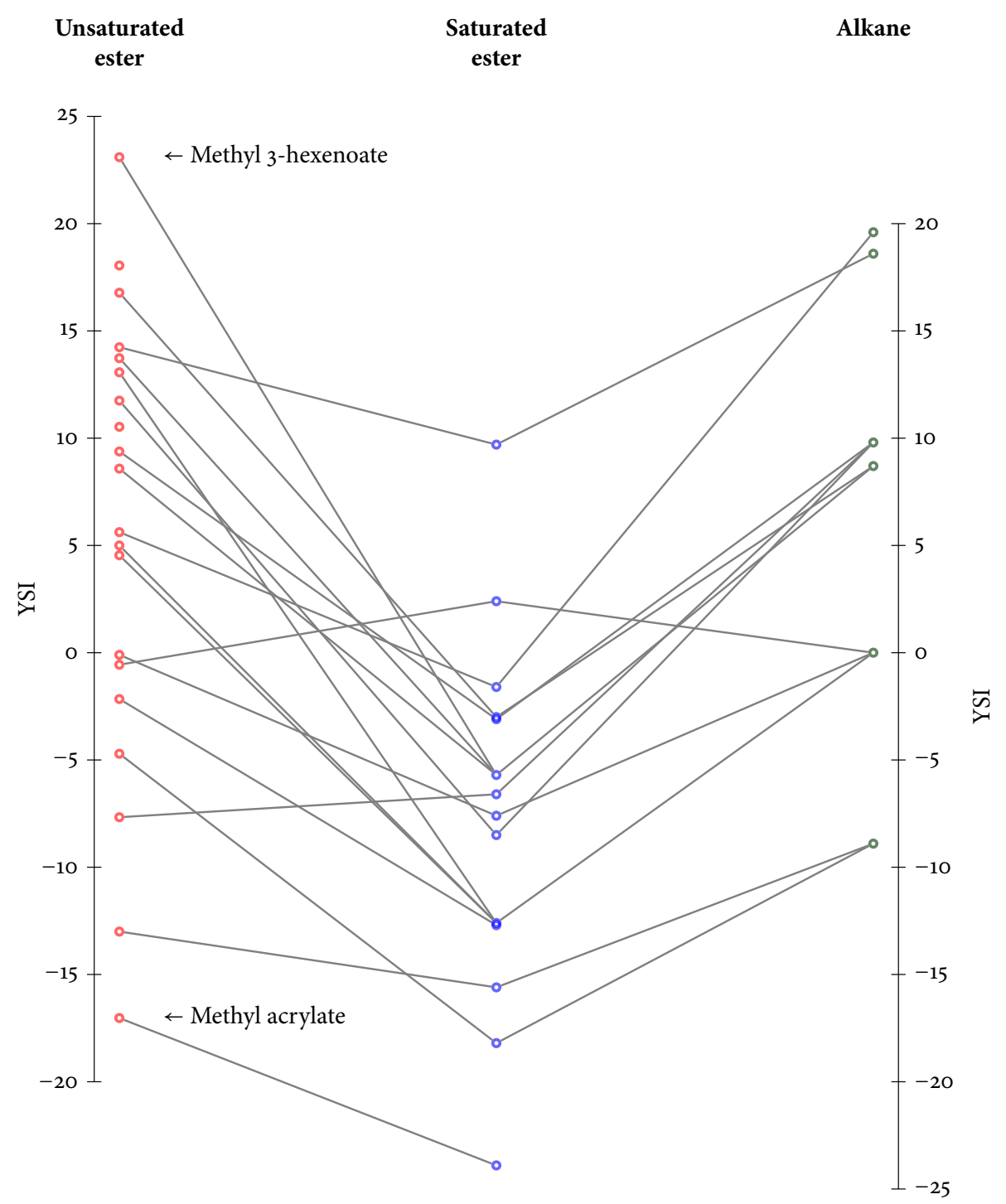

Figure 4: Slopegraph depicting YSI of unsaturated esters (॰, this study), saturated esters $(\bullet$, from [14]), and alkanes ( $\bullet$, from [14]). Lines connect unsaturated esters and their counterpart saturated esters and parent alkanes, e.g. methyl 3-pentenoate $\leftrightarrow$ methyl pentanoate $\leftrightarrow$ hexane. 


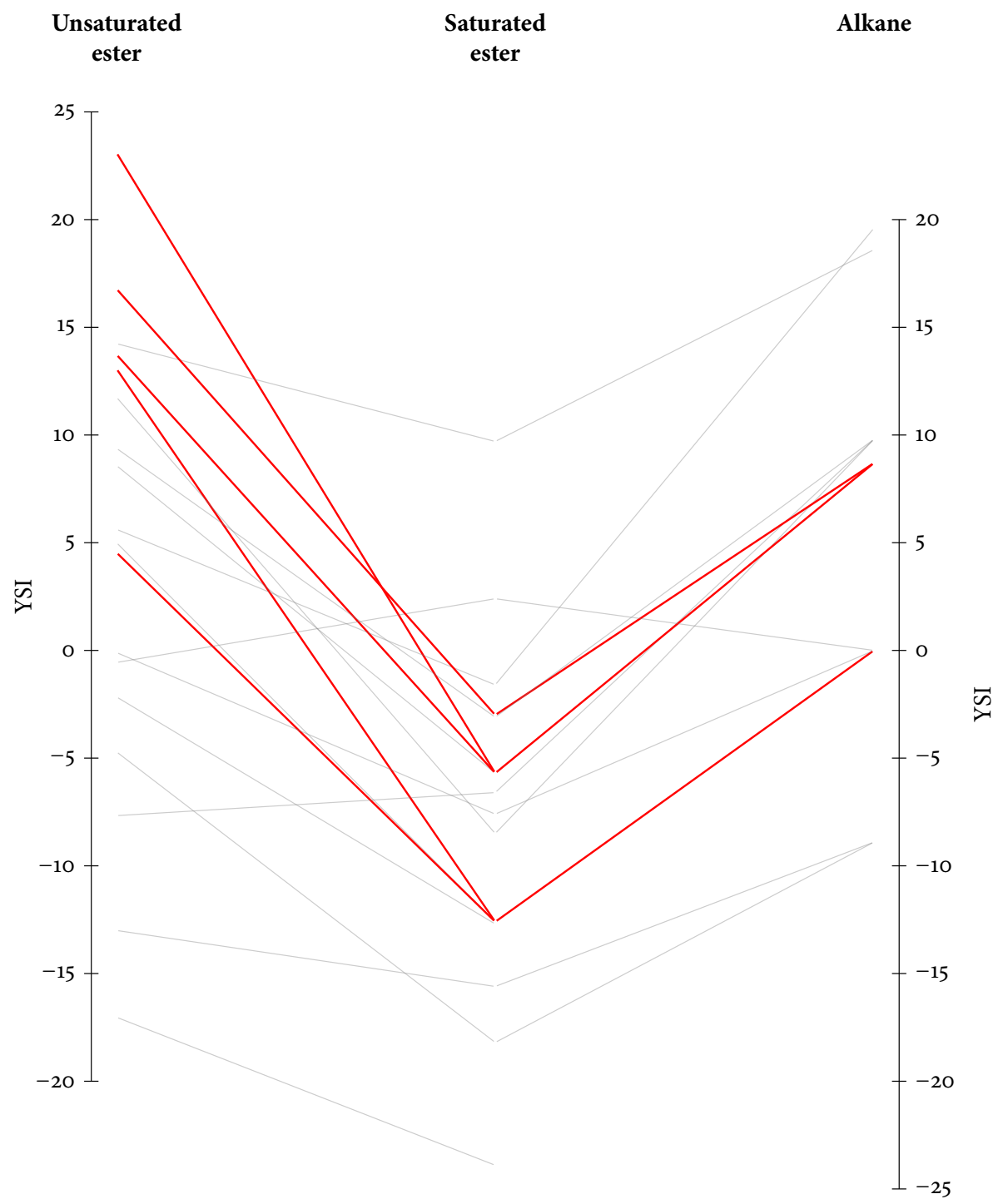

Figure 5: Slopegraph depicting YSI of unsaturated esters (this study), saturated esters, and alkanes (from [14]). Lines highlighted in red connect alkanes and saturated esters with unsaturated esters where the $\mathrm{C}=\mathrm{C}$ double bond is not on the carbon atom next to the carbonyl group. 


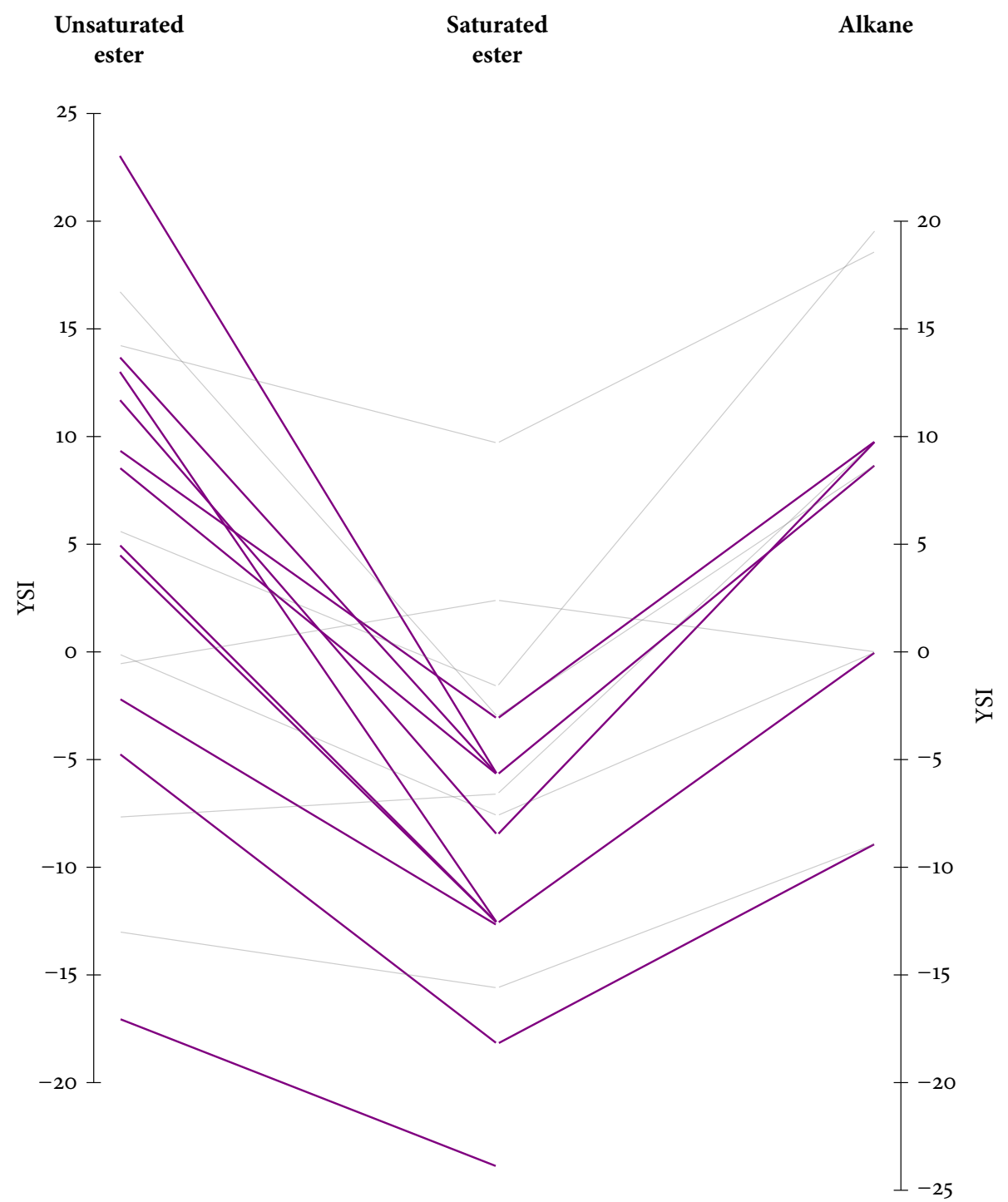

Figure 6: Slopegraph depicting YSI of unsaturated esters (this study), saturated esters, and alkanes (from [14]). Lines highlighted in purple connect alkanes with saturated and unsaturated methyl esters. Gray lines indicate ethyl and propyl saturated and unsaturated esters. 


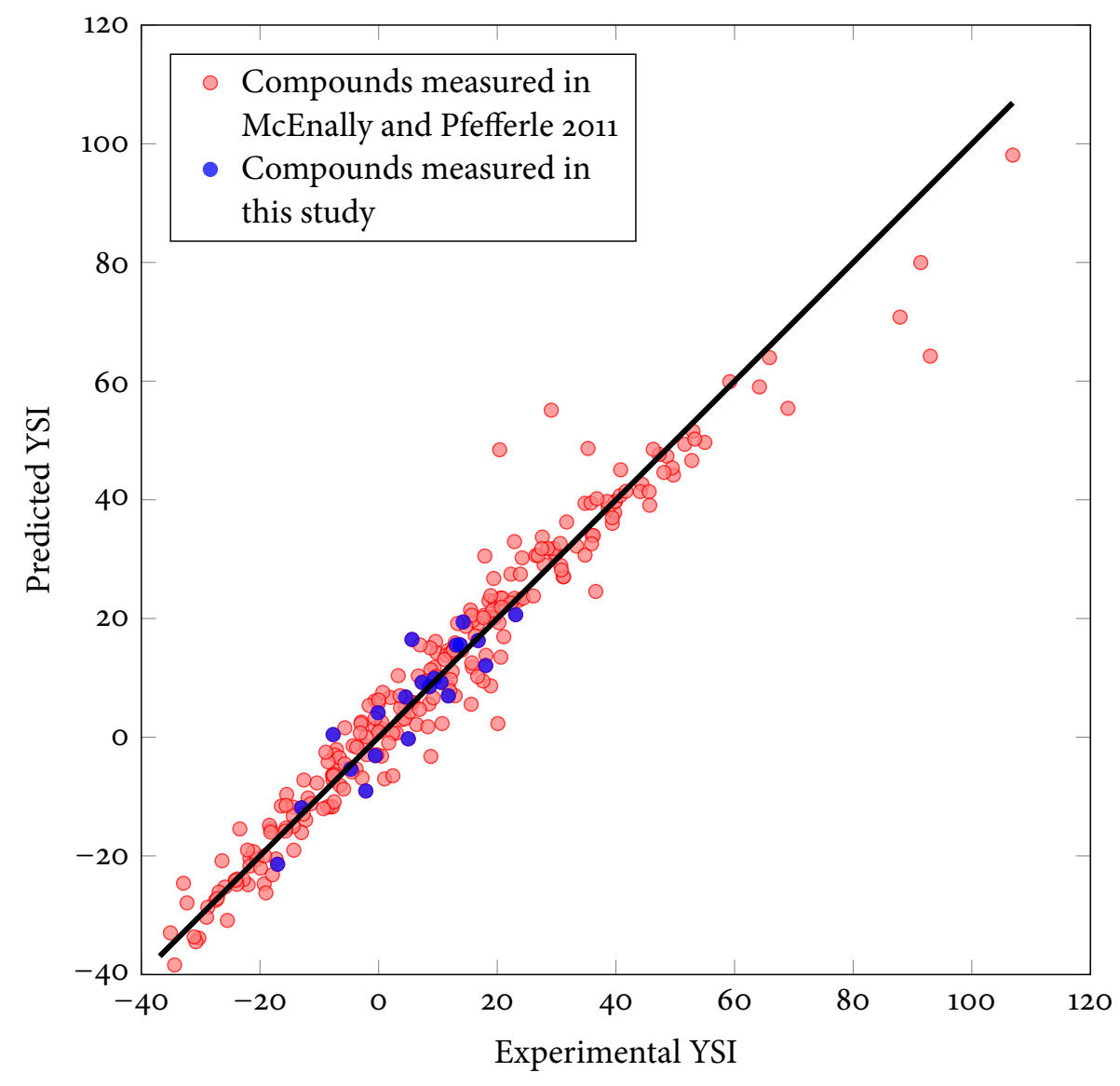

Figure 7: Correlation between YSI of 265 compounds, predicted with Eq 2 using optimized group contribution values $C_{j}$, and measured experimentally. Data points highlighted in blue are for unsaturated esters measured in this study. The black line is the $x=y$ line. $R^{2}=0.95$ 


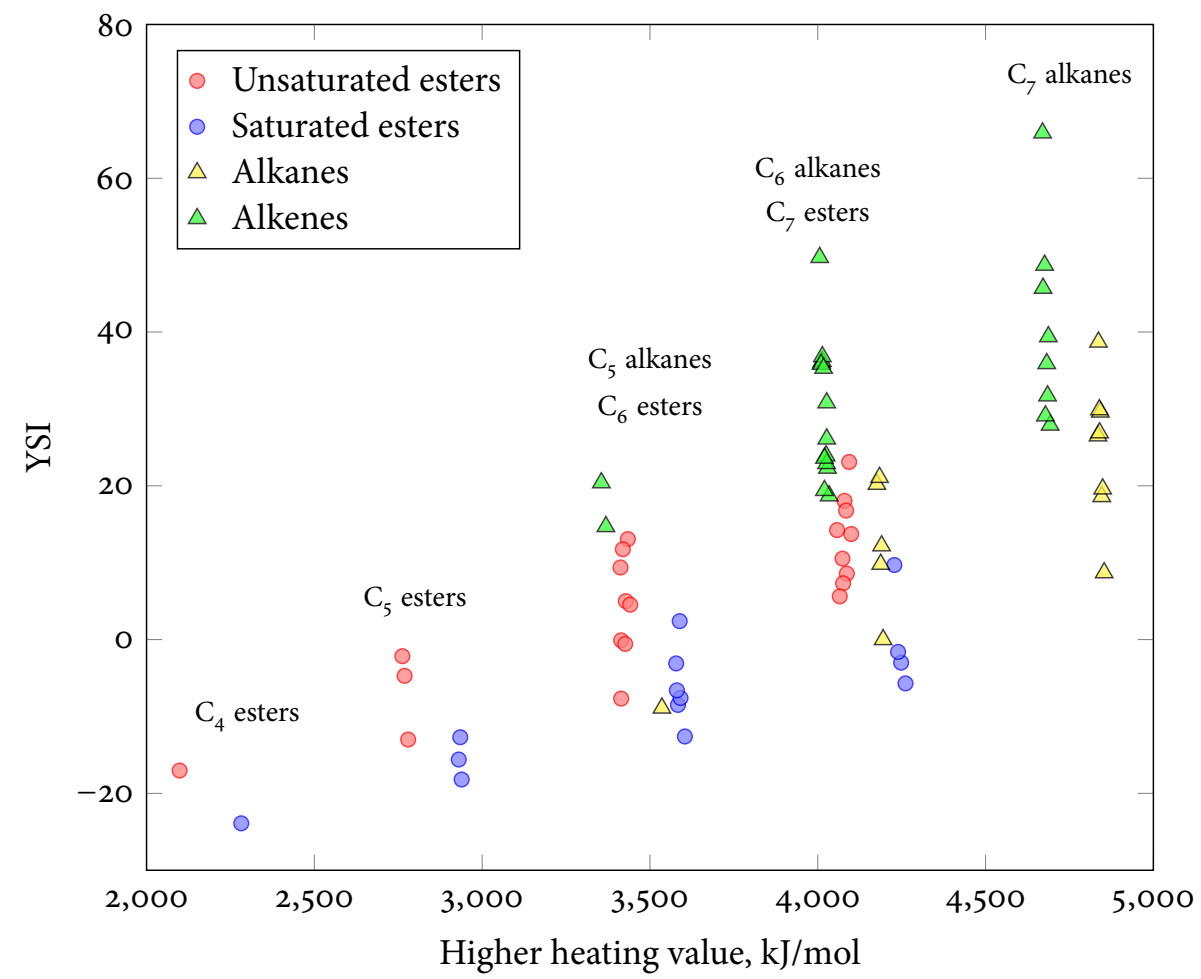

Figure 8: Variation of sooting tendency of alkanes, alkenes, saturated and unsaturated esters with their molar higher heating values. YSI data for alkanes, alkenes, and saturated esters are from [14] and for unsaturated esters from this work. Higher heating values were calculated using gas phase heat of formation of individual compounds from [51]. $\mathrm{C}_{5}, \mathrm{C}_{6}, \mathrm{C}_{7}$ alkanes annotation also applies to alkene data points. 


\section{References}

[1] D. W. Dockery, C. A. Pope, X. Xu, J. D. Spengler, J. H. Ware, M. E. Fay, B. G. Ferris, F. E. Speizer, The New England Journal of Medicine 329 (1993) 1753-9.

[2] J. M. Samet, F. Dominici, F. C. Curriero, I. Coursac, S. L. Zeger, The New England Journal of Medicine 343 (2000) 1742-9.

[3] C. A. Pope, R. T. Burnett, M. J. Thun, E. E. Calle, D. Krewski, K. Ito, G. D. Thurston, JAMA : the journal of the American Medical Association 287 (2002) 1132-41.

[4] S. S. Lim, T. Vos, A. D. Flaxman, G. Danaei, K. Shibuya, H. Adair-Rohani, Others, Lancet 380 (2012) 2224-60.

[5] T. C. Bond, S. J. Doherty, Others, Journal of Geophysical Research: Atmospheres 118 (2013) 5380-5552.

[6] D. Olson, J. Pickens, R. Gill, Combustion and Flame 62 (1985) 43-60.

[7] A. Gomez, I. Glassman, Proceedings of the Combustion Institute 21 (1986) 1087-1095.

[8] N. Ladommatos, P. Rubenstein, P. Bennett, Fuel 75 (1996) 114-124.

[9] K. M. Allan, J. R. Kaminski, J. C. Bertrand, J. Head, P. B. Sunderland, Combustion Science and Technology 181 (2009) 800-811.

[10] H. Calcote, D. Manos, Combustion and Flame 49 (1983) 289-304.

[11] E. J. Barrientos, M. Lapuerta, A. L. Boehman, Combustion and Flame 160 (2013) 1484-1498.

[12] C. S. McEnally, L. D. Pfefferle, Combustion and Flame 148 (2007) 210-222.

[13] C. S. McEnally, L. D. Pfefferle, Proceedings of the Combustion Institute 32 (2009) 673-679.

[14] C. S. McEnally, L. D. Pfefferle, Environmental Science and Technology 45 (2011) 2498-503.

[15] M. Kashif, P. Guibert, J. Bonnety, G. Legros, Combustion and Flame 161 (2014) $1575-1586$.

[16] Y. Xuan, G. Blanquart, Combustion and Flame 160 (2013) 1657-1666.

[17] A. Mensch, R. J. Santoro, T. a. Litzinger, S.-Y. Lee, Combustion and Flame 157 (2010) 1097-1105.

[18] K. Kohse-Höinghaus, P. Osswald, T. a. Cool, T. Kasper, N. Hansen, F. Qi, C. K. Westbrook, P. R. Westmoreland, Angewandte Chemie (International ed. in English) 49 (2010) 3572-97. 
[19] C. K. Westbrook, Annual review of physical chemistry 64 (2013) 201-19.

[20] A. Demirbas, Progress in Energy and Combustion Science 33 (2007) 1-18.

[21] P. Pepiot-Desjardins, H. Pitsch, R. Malhotra, S. R. Kirby, A. Boehman, Combustion and Flame 154 (2008) 191-205.

[22] M. Lapuerta, O. Armas, J. M. Herreros, Fuel 87 (2008) 25-31.

[23] S. Sarathy, S. Gaïl, S. Syed, M. Thomson, P. Dagaut, Proceedings of the Combustion Institute 31 (2007) 1015-1022.

[24] S. Gaïl, S. Sarathy, M. Thomson, P. Diévart, P. Dagaut, Combustion and Flame 155 (2008) 635-650.

[25] B. Yang, C. K. Westbrook, T. A. Cool, N. Hansen, K. Kohse-Höinghaus, Zeitschrift für Physikalische Chemie 225 (2011) 1293-1314.

[26] B. Yang, C. K. Westbrook, T. A. Cool, N. Hansen, K. Kohse-Höinghaus, Physical chemistry chemical physics : PCCP 13 (2011) 6901-13.

[27] B. Yang, C. K. Westbrook, T. A. Cool, N. Hansen, K. Kohse-Höinghaus, Proceedings of the Combustion Institute 34 (2013) 443-451.

[28] K. Zhang, C. Togbé, G. Dayma, P. Dagaut, Combustion and Flame 161 (2014) 818-825.

[29] O. Herbinet, W. J. Pitz, C. K. Westbrook, Combustion and Flame 154 (2008) 507-528.

[30] O. Herbinet, W. J. Pitz, C. K. Westbrook, Combustion and Flame 157 (2010) 893-908.

[31] C. Westbrook, C. Naik, O. Herbinet, W. Pitz, M. Mehl, S. Sarathy, H. Curran, Combustion and Flame 158 (2011) 742-755.

[32] S. Garner, K. Brezinsky, Combustion and Flame 158 (2011) 2289-2301.

[33] C. Westbrook, W. Pitz, S. Sarathy, M. Mehl, Proceedings of the Combustion Institute 34 (2013) 3049-3056.

[34] J. Y. Lai, K. C. Lin, A. Violi, Progress in Energy and Combustion Science 37 (2011) 1-14.

[35] Q. Feng, A. Jalali, A. M. Fincham, Y. L. Wang, T. T. Tsotsis, F. N. Egolfopoulos, Combustion and Flame 159 (2012) 1876-1893.

[36] S. W. Benson, Thermochemical Kinetics: Methods for the Estimation of Thermochemical Data and Rate Parameters, Wiley, New York, 2 edition, 1976.

[37] S. W. Benson, J. H. Buss, The Journal of Chemical Physics 29 (1958) 546. 
[38] N. Cohen, S. W. Benson, Chemical Reviews 93 (1993) 2419-2438.

[39] E. Lemmon, M. McLinden, D. Friend, in: P. Linstrom, W. Mallard (Eds.), NIST Chemistry WebBook, NIST Standard Reference Database Number 69, National Institute of Standards and Technology, Gaithersburg MD, 20899, 2014 .

[40] Sigma-Aldrich Corporation, http://www.sigmaaldrich.com/unitedstates.html, ????

[41] TCI-America Corporation, http://www.tcichemicals.com/en/us/, ????

[42] B. Quay, T.-W. Lee, T. Ni, R. Santoro, Combustion and Flame 97 (1994) 384-392.

[43] K. Thomson, D. Snelling, G. Smallwood, F. Liu, Applied Physics B 83 (2006) 469-475.

[44] F. Goulay, P. E. Schrader, X. López-Yglesias, H. A. Michelsen, Applied Physics B 112 (2013) 287-306.

[45] P. Desgroux, X. Mercier, K. A. Thomson, Proceedings of the Combustion Institute 34 (2013) 1713-1738.

[46] B. Menkiel, A. Donkerbroek, R. Uitz, R. Cracknell, L. Ganippa, Fuel 118 (2014) 406-415.

[47] R. L. Vander Wal, K. J. Weiland, Applied Physics B 59 (1994) 445-452.

[48] C. Schulz, B. Kock, M. Hofmann, H. Michelsen, S. Will, B. Bougie, R. Suntz, G. Smallwood, Applied Physics B 83 (2006) 333-354.

[49] A. Nigam, M. T. Klein, Industrial and Engineering Chemistry Research 32 (1993) 1297-1303.

[50] B. E. Poling, J. M. Prausnitz, J. P. O'Connell, The Properties of Gases and Liquids, McGraw-Hill, New York, 5 edition, 2001.

[51] D. Burgess, in: P. Linstrom, W. Mallard (Eds.), NIST Chemistry WebBook, NIST Standard Reference Database Number 69, National Institute of Standards and Technology, Gaithersburg MD, 20899, 2014. 